\title{
РЕЦЕНЗИИ
}

\author{
МИХАЙЛОВА Юлия Дмитриевна \\ канд. ист. наук, почётный профессор Муниципального Университета г. Хиросима (Япония) \\ Электронная почта: yuliamikjapan@gmail.com
}

\section{О культурной составляющей современных учебников японского языка}

УДК 81

doi: dx.doi.org/10.24866/2542-1611/2020-3/122-136

японский как иностранный,

культурный компонент, межкультурная компетенция, учебник
В статье приводится сравнительный анализ культурных компонентов двух учебников японского языка - японского и российского по методу контент-анализа по шкале М. Байрона. Российский учебник сосредоточивает внимание только на японской культуре, но в то же время вычленяет пласты жизни общества, из которых «вырастают» ценностные ориентации и особенности мышления. Материал японского учебника позволяет показать японскую культуру в сопоставлении с другими, дает возможность расширить межкультурную компетентность; его можно использовать как подспорье для работы и жизни в Японии. В статье даются рекомендации, позволяющие усовершенствовать процесс включения культурного компонента

Статья подготовлена при финансовой поддержке Японского общества содействия науке, проект № К0 172030, руководитель проекта Ю. Д. Михайлова

Для ииттирования:

Михайлова Ю. Д. О культурной составляющей современных учебников японского языка // Известия Восточного института. 2020. № 3. C. 122-136. doi: dx.doi. org/10.24866/2542-1611/2020$3 / 122-136$

\section{Введение}

В последние несколько десятилетий под влиянием процесса глобализации при изучении иностранных языков появилась необходимость знать не только речевые модели и языковые структуры, но и то, что «лежит за языком», то есть культуру [2].

Термин «культура» имеет несколько значений. Одно из них уходит корнями в гуманитарные науки и связано с достижениями человечества, такими как литература, искусство, философия и тому подобное. Часто это называется «глубокой культурой» или культурой с большой буквы. Второе значение происходит из социальных наук и относится к ценностным ориентациям, представлениям о нравственности, привычкам, усвоенными человеком как членом какого-либо сообщества. Это культура с прописной буквы и проявляется она скорее в повседневной жизни. По утверждению профессора университета Беркли Клэр Крамш, культура выражается посредством языка и именно она делает людей одной социальной или этнической группы отличными от других, составляя основу их идентичности и мировоззрения [10]. Крамш указывает, что культурная информация в учебниках не должна ограничиваться фактами по географии, рассказами о знаменитых людях, известных исторических местах и событиях. В своих трудах она проводит идею о том, что приобретение другого иностранного языка может быть удачным лишь в том случае, если оно влечет за собой приобретение «культурной осведом- 
ленности», а именно, поведенческих навыков, понятий о системе ценностей, верований и т. п.

Новая парадигма в понимании соотношения языка и культуры предъявляет новые требования к учителям и их «орудию труда» учебникам. При довольно обширном теоретическом анализе необходимости со-изучения языка и культуры еще слабо разработана технологическая сторона этого процесса, то есть методика преподавания, и вопрос о том, каким должно быть содержание учебников [8].

Считается, что именно учебники с их авторитетом должны показать образцы преподавания, дать «правильное и объективное» знание, хотя известно, что на самом деле каждый учебник несет в себе определенную идеологию, имеет свою «скрытую программу» [14]. В создании учебников задействованы интересы многих сторон - учителей, авторов, редакторов, издателей, дизайнеров, а также тех, кто руководит вопросами образования в области изучения иностранных языков [11]. Наличие такого большого количества заинтересованных лиц порождает споры, каким должен быть учебник иностранного языка, как конкретно можно сочетать преподавание языка с преподаванием культуры.

\section{Методы исследования}

Автор настоящей статьи исходит из того, что культура, как с прописной, так и с большой буквы должна входить в материалы учебников иностранных языков, но при разных целях обучения это может происходить по-разному. Задачей статьи является показать и проанализировать образцы того, как, какой культурный материал, каким образом и с какой целью может подаваться студентам. Представляется, что это особенно важно сделать на примере учебников японского языка потому, что большинство исследований в области изучения культурного компонента относится к преподаванию английского языка как наиболее распространенного в мире [12].

В статье дается сравнительный анализ культурной составляющей двух учебников японского языка: одного, выпущенного Институтом Стран Азии и Африки при МГУ [1; 3], второго, выпущенного в Японии и используемого в 13 странах мира [16; 17]. Эти учебники были признаны наилучшими во время опросов, проведенных в 2018-2019 гг. среди изучающих японский язык в Москве, Санкт-Петербурге, Казани и Владивостоке (всего 400 человек). Нам интересно выяснить, что именно привлекает студентов к этим учебникам и как они формируют представления о мире вообще и Японии в частности.

Для сравнения нами были отобраны вторые части учебников для начинающих, где впервые появляются связные диалоги и тексты, и первые части учебников для продолжающих, где фигурируют специальные тексты на культурологическую проблематику. Для анализа культурной составляющей был использован метод контент-анализа по шкале М. Байрома, являющийся наиболее распространенным [6; 15]. Ограниченность в объеме статьи не позволила продемонстрировать контент-анализ учебников для продолжающих.

\section{«Японский для всех", учебник для начинающих, ч. 2}

Главные «действующие лица» японского учебника [16; 17] - сотрудники компьютерных компаний IMC и Power Denki. Среди них имеются как японцы, так и представители других стран: американец Майкл Миллер, таиландец Тавапон, кореянка Ли, немец Карл Шмидт, его жена Клара, преподаватель немецкого языка, их сын Ганс, англичанин 
1 В круглых скобках указана частотность употребления слов.
Джон Ватт, преподаватель английского языка в университете Сакура, школьная учительница Ганса Ито-сан, и наконец сотрудники Центра по изучению проблем Азии. Таким образом, «действующие лица» относятся к среднему классу и являются профессионалами. Представления о Японии как стране «среднего класса» появились в период экономического роста (1960-1980-х гг.) и, как видно, продолжали существовать в конце 1990-х гг., когда был создан учебник, хотя после краха экономики «мыльного пузыря» (1991 г.) в Японии усугубилось социальное неравенство, но в учебнике это никак не отражено. Ни $\oint p$ ретерь, ни те, кто занимается собственным бизнесом, в учебнике не представлены. Нет и людей, обладающих недвижимостью в больших размерах. Другими словами, учебник поддерживает иллюзию того, что японское общество состоит из «среднего класса».

Это отражается и в языке. По частотности употребления первое место заняло понятие «собрание» $(14)^{1}$. Тематически сюда же можно отнести и некоторые виды совместной деятельности: «групповой отдых» (2), «проводы старого года (4)», совместные посещения ресторанов и баров, проведение вечеринок (9). Региональная идентичность (например, диалекты) или принадлежность к этническому меньшинству Японии нигде не указана.

Хотя этнические границы групп внутри Японии не фиксированы, этническое неравенство между японцами и иностранцами присутствует. Еще в XIX веке Япония усвоила американскую расовую иерархию, то есть «белые» иностранцы имели больший престиж, чем цветные.

Этот же подход присутствует и в «Японском для всех». Американец Миллер пользуется всеобщим уважением, периодически отмечаются его «выдающиеся способности» (4). Так, он побеждает в конкурсе на ораторское мастерство, быстро овладевает японским языком, умеет сам изготовлять мебель, занимает второе место в марафоне. Вместе с тем Миллер отказывается заниматься английским языком с сыном японского сотрудника фирмы, что в принципе можно отнести к отрицательной характеристике этого персонажа. Таиландец Тавапон пользуется любовью сотрудников за свою отзывчивость и готовность помочь другим, но проваливается на экзамене по японскому языку.

В Японии 1980-1990-х гг. считался проблематичным вопрос об отношении к детям иностранцев, учащихся в японских школах, или к детям японцев, которые вернулись в Японию после обучения за границей. Однако сын Шмидтов, несмотря на волнения родителей, хорошо вписывается в школьный коллектив и проводит много времени с японскими друзьями за пределами школы (3) [9].

Социальная интерактивность: сотрудники фирмы IMC - японцы и иностранцы - взаимодействуют не только на работе, но и после окончания рабочего дня и в выходные. Чаще всего это происходит во время совместных выпивок после работы, хотя отказы от подобных мероприятий появляются в учебнике неоднократно (5). Это может являться свидетельством того, что практика обязательных совместных выпивок стала отходить в прошлое.

Среди товаров (11), которые покупают «действующие лица», чаще всего фигурируют предметы первой необходимости (еда и одежда). Повседневная пища и одежда, как правило, являются японскими, но среди предметов роскоши фигурируют иностранные товары (сумка, 
шляпа, вино) (3). Сырьё для промышленности поступает в Японию из-за рубежа (2) - это нефть из Саудовской Аравии.

Среди верований упоминается посещение христианской церкви (3) и предсказание судеб (1). Последнее выделено в виде отдельного рассказа, что, вероятно, подчеркивает особую важность данной темы. Текст на аналогичную тему есть и в российском учебнике. Упоминание христианской религии может свидетельствовать о стремлении японцев отождествить себя с Западом.

По теме «изобретения и архитектура» фигурируют такие примеры, как «растворимая лапша» (кап рамэн) и растворимый кофе. Из японских умельцев преподносится только резчик по дереву Хидари Дзингоро, который прославился тем, что левой рукой вырезал фигуру спящей кошки для храма Тосёгу в Никко. Неоднократно отмечается, что аэропорт Кансай (3), был построен итальянцами, а самолет изобретен братьями Райт (1).

В разделе о социализации и жизненном цикле чаще всего упоминается тема бракосочетания (12), но только 1 раз говорится о рождении ребёнка. В принципе, такое соотношение отражает современную тенденцию к уменьшению рождаемости в Японии, но разница между браком и отсутствием стремления иметь детей не находится в таких больших пропорциях. Проблема гендерных отношений в учебнике практически отсутствуют, за исключением упоминания о нежелании мужчин участвовать в приготовлении пищи (2), хотя дети это делают неоднократно (3). Важный момент в жизненном цикле - приобретение собственного дома, на который каждый японец копит деньги (3). Однако принципиальный вопрос, что лучше - иметь хорошую работу или благоустроенный дом остается без ответа.

Дважды заходит разговор о ностальгии: один раз вспоминаются места детства, другой раз приводится рассказ о лошадях как животных, которые в прошлом не только были нужны человеку, но привлекали своей красотой и статью. Кажется странным, что тема приобретения машины ни разу не поднимается.

Разговоры об иностранной культуре/природе возникают (14) раз, в том числе о картинах Пикассо и Ван Гога, мюзикле на Бродвее, слонах и жирафах в Африке. Японцы постоянно горят желанием изучать иностранные языки: китайский (3), вьетнамский (1), французский (1), испанский (1), английский (4).

По теме «национальная история и современные события как маркеры национальной идентичности» картина предстает такая: символы Японии упоминаются 10 раз, это ханами, икэбана, праздник Гион, памятники архитектуры (Кинкаку-дзи и Никко) и т. п. - все они относятся к разряду традиционной культуры. Интересно, что кимоно, так прочно ассоциирующееся с Японией, критикуется как неудобный вид одежды. Положительной оценки заслуживают храм Тосёгу в Никко (3) и музей периода Эдо, находящийся в Токио (2).

Разговор о болезни и посещение врача упоминается 3 раза, но землетрясение и тайфун как национальный географический фактор фигурируют 9 раз.

Учебник довольно индифферентен к политической проблематике. Обсуждение проблем войны и мира упоминается 2 раза, один раз говорится о подготовки конференции на тему «будущего Японии». Один из персонажей едет в Америку изучать японо-американские 
отношения, а другой хочет изучать в Америке отношения Японии со странами Азии.

Среди «недостатков или отрицательных сторон жизни» упоминается отсутствие мыла и полотенца в гостинице (1), плохая работа автоматов по продаже билетов (3), и трудности утреннего пробуждения (1), необходимость внеурочной работы (4) и слишком короткий летний отпуск (3). Дважды рассказывается об автомобильных авариях, один раз об аварии на железной дороге (2). Упоминается горный пожар в Калифорнии (1), авиационная катастрофа на Гуаме (1), землетрясение в Иране (1).

В целом Япония рисуется как общество вежливых и бесконфликтных людей. В заключении делается вывод, что жизнь в Японии удобная, но дорогая. Однако было бы неверно думать, что все понятия, вошедшие в список контент-анализа, действительно соответствуют частоте их «присутствия» в реальной жизни. К врачам обращаются гораздо чаше, а рассказ о трудностях утреннего пробуждения является просто шуткой.

Когда создавался учебник «Японский для всех», в Японии было популярным слово «интернационализация». Японцы одними из первых в мире стали ее приветствовать. Нефтяной кризис 1970-х гг. заставил почувствовать, насколько японская экономика зависит от поставок сырья из-за рубежа, и осознать, что международное экономическое сотрудничество является жизненно необходимым для развития экономики страны. Для Японии «интернационализация», выражалась и в надежде на то, что ее перестанут называть «экономическим чудовищем», где люди-трудоголики живут в квартирах, похожих на кроличьи норы. Япония стремилась поднять свой статус на международной арене. Заимствуя метафору книги Сибата Тосихару «Японский человек и международный человек», Рональд Дор указывает, что «интернационализация» была средством «стать международным человеком в шесть футов ростом [то есть как западные люди - Ю. М.], но не утратить при этом своей японской сущности» [7]. «Интернационализация» включала и переход на западные образцы культуры в повседневной жизни. Японцы стали запросто употреблять западные напитки, носить западную одежду или обставлять свое жилье на западный манер, активно учились английскому. Страна стремилась к тому, чтобы «интернационализация» включала и сферу образования, а именно, чтобы больше японских студентов училось за границей, а иностранцы могли преподавать в Японии. До тех пор официально только японцы могли занимать должности в японских университетах. Те же, кто знал английский язык, выучив его за рубежом, чувствовали свою отгороженность от остальных японцев и могли работать только на специальных должностях, где знание иностранных языков было необходимостью.

Идея работы иностранцев в японских фирмах, предложенная в учебнике «Японский для всех» в качестве главной темы, была довольно удачным примером «интернационализации». Однако в текстах не поднимаются никакие социальные или культурные проблемы, связанные с этим процессом. Было бы неплохо увидеть сотрудников фирмы в процессе рабочего взаимодействия, хотя бы Клару Шмидт, преподающую немецкий язык, или Ито-сан, обучающих иностранцев японскому. Нередко говорится о том, кто и куда собирается поехать за границу, но эти высказывания могли бы быть дополнены фотогра- 
фиями какого-либо известного памятника архитектуры в Париже или в Нью-Йорке. Известно, что японцы в то время любили делать фотографии типа «Я на фоне Эйфелевой башни», и японец с фотоаппаратом в руках стал своеобразным международным клише. Вместо этого в учебнике тиражируются изображения храма Тосёгу в Никко.

\section{«Японский для всех», часть для продолжающих, 1}

Учебник для продолжающих включает не только тексты о культуре Японии, но и о других странах.

В первом рассказе сотрудник фирмы IMC Тавапон хочет увидеть традиционный японский дом и обращается с просьбой к соседке. Несколько других «действующих лиц» учат его, как это сделать наиболее вежливо. Далее следует его рассказ, где раскрывается тема maтами.

В настоящее время многие считают, что полы в японских комнатах всегда были покрыты татами. Это слово настолько прочно ассоциируется с Японией, что во Франции знатоки японского языка даже зовутся tatamiser. Однако оказывается, что такое представление о татами ошибочно. В старину полы во всех домах были сделаны из досок, а татами играли роль современных дзабутонов - мягких стульев для сиденья. Коврики татами накладывались один на другой. При необходимости их могли перенести в другую комнату, например, в кабинет для работы. Авторы учебника для наглядности дают иллюстрации старинного и современного домов.

Студентам предлагается рассказать о подобных же превращениях предметов старинной культуры быта в современные в их странах и написать сочинение на соответствующую тему. Таким образом, учащимся предоставляется возможность познакомиться с культурным разнообразием разных стран.

Если первый урок рассказывает об изменении вещей во времени, то второй поднимает тему распространения знаний в пространстве на примере заимствования японцами иностранных слов, несмотря на то, что существуют исконные японские слова с таким же значением. Например, слово «мягкий» (soft) стало частью компьютерного понятия «software», но в остальных случаях употребляется исконно японское слово «яваракай». Или же английское слово «эко» часто заменяет японское слово «канкё» (окружающая среда). Слово «апо», сокращение от «арpointment» стало употребляться вместо японского «ёяку».

Автор этого текста критикует японцев за бездумное использование слов, заимствованных из английского языка и записанных катаканой. В некоторых случаях японцы путаются в значениях слов, например, «копи-» (копия) и «ко-хи-» (кофе). Однако заимствованных слов стало настолько много, что имеется их отдельный словарь, и вряд ли современные японцы могут без них обойтись. Вместе с тем автор статьи прав в том, что японцы не всегда понимают нюансы значений английских терминов, например, таких как identity, policy, compliance, но отказываются от употребления японских слов, имеющих то же значение [17, с. 26-27]. Студентам предлагается рассказать, как происходит заимствование иностранных слов в их стране.

Забавен рассказ о Марке Твене, который никак не хотел признать пользу телефона, изобретенного другим знаменитым американцем Александром Беллом, но все же вынужден был сделать это, стоило 
телефону понадобиться самому писателю в жизни. Так, в шуточной форме говорится о том, как случай другой раз помогает внедрению изобретений в жизнь. Тут же приводится несколько картинок с телефонами и студентам предлагается расставить их по порядку изменения моделей во времени [17, с. 54-55].

Образец культурного релятивизма даётся на примере географических карт. Западные люди по умолчанию привыкли, что на географических картах север изображен сверху, но для одного преподавателя из Австралии, приехавшего в Японию в 1879 г., это оказалось шоком. Тогда он нарисовал карту, где Австралия находилась сверху. Составители учебника замечают, что изображение севера наверху могло быть не случайным, а выражало дискриминацию со стороны европейцев, и в свою очередь предлагают карты с Африкой и Южной Америкой, нарисованными наверху, а учащиеся должны задуматься о причинах такого явления [17, с. 68].

Другой пример разнообразия мышления и трактовки восприятия заимствован из газеты «Асахи». В 32 странах мира был проведён опрос на тему, какими дети представляют себе ученых. В ответах имелось несколько рисунков, среди которых учеными были изображены женщины, что оказалось для многих неожиданностью. В то же время выявилось, что в развитых странах образ ученых, как правило, мрачный и отрицательный и бывает связан с атомной бомбой. В Японии же, возможно, именно по этой причине, никто из детей вообще не стремится стать ученым-испытателем. Наоборот, в развивающихся странах образ учёных положительный. В конце текста задается вопрос: «Что делать, чтобы развитие науки не наносило ущерб развитию человечества?» [17 с. 110-113]. Надо признать, что это довольно актуальный вопрос.

Составители учебника с особой гордостью подают образцы культуры своей собственной страны, как современные, так и более старинные, но мало известные. Так, слово караоке вместе со словами дзюдо и иунами давно вошли в мировой лексикон, а изобретатель караоке Иноуэ Дайскэ наряду с Ганди и Мао Цзэдуном был причислен журналом «Тайм» к двадцати представителям Азии, оказавшим влияние на XX век. Авторы учебника подчеркивают, что караоке представляет собой гордость японской культуры [17 с. 123-124]. Однако такое заключение может многим показаться кощунством.

А вот рассказ о деревне Сиракава, находящейся высоко в горах префектуры Гифу, действительно вызывает восхищение гением японского народа. В этих заснеженных краях крыши домов были остроконечными словно руки, сложенные в молитве. Под крышами можно было выращивать шелковичных червей и хранить сырьё для пороха. Рис в горах не произрастал, крестьяне не платили налоги, но жили безбедно, так как могли добывать золото и серебро в горах. Только в $\mathrm{XV}$ в. сюда пришли правители из рода Ода Нобунага. Однако в конце XVI в. случилось сильное землетрясение и все погибли. Сохранилась легенда, что где-то якобы остался замок, полный золота, но его до сих пор не обнаружили. В 1995 г. остроконечные дома были собраны вместе и внесены в список культурного наследия ЮНЕСКО. Сейчас это место стало объектом паломничества туристов со всего мира, что явно способствует развитию межкультурной компетенции. 
Таким образом, тексты этого тома «Японского для всех» вводят разнообразную культурологическую проблематику. Одни из них рассказывают об уникальных образцах национальных культур, и прежде всего японской, другие обращают внимание на то, что в современном глобальном мире между людьми, принадлежащими к разным культурам и говорящим на разных языках, идет процесс взаимодействия и обмена, как это хорошо видно на примере языковых заимствований.

\section{Учебник японского языка МГУ}

Если ли «Японский для всех» написан в полушуточном тоне и в нём нередко присутствует прямое обращение к учащимся, то учебник МГУ хранит научные традиции времен господства грамматико-переводного метода. В нём много подробных и дотошных объяснений грамматики, упражнений на перевод с русского языка на японский. Словари уроков насчитывают около 2000 лексических единиц, но, вероятно, только очень добросовестный студент в состоянии объять всё это многообразие.

Тексты составлены на основе реалий сегодняшнего дня и в основном рассказывают об обучении российских студентов в одном из японских университетов и их жизни в Японии. Для обучения выбраны следующие темы: времена года, география Японии, политические системы Японии и России, национальные праздники в обеих странах, путешествие на скоростном поезде из Токио в Киото, спорт, книжный магазин, покупки, японская кухня, служба быта, экскурсии по Токио и Москве, Киото и Петербургу. Большинство тем раскрываются параллельно на японском и российском материалах. Именно такая или примерно такая схема уроков была предложена в начале 1970-х гг. в учебнике «Учебнике японского языка» под редакцией И. В. Головнина, который, правда, имел значительно более сильный уклон в российскую, чем японскую, тематику. Тогда это объяснялось тем, что в те годы из России в Японию могло попасть лишь небольшое число людей - помимо дипломатических представителей ими были корреспонденты газет и радио, деятели культуры. Из Японии же в Россию уже ездили туристы, в основном делегации профсоюзов, и для них нужны были гиды-переводчики, которых и готовил учебник. Кроме того, здесь сказывалась и идеологическая установка того времени - стремление показать превосходство Советского Союза.

В отличие от советского учебника, в постсоветском учебнике идеологическая составляющая полностью отсутствует - всё подано политически и идеологически безукоризненно. Однако, возможно, именно такая «корректность» делает учебник несколько однообразным. Головнин и его коллеги в своё время попытались оживить текст, придумав, например, в теме «Покупки» интересный ход: японцы, чуть ли не все подряд, покупали в России шапки-ушанки, рукавицы и башмаки $[4$, с. 156]. Это давало повод посмеяться - ведь полки советских магазинов были практически пустыми, а образ японца в шапке-ушанке вполне мог вызвать улыбку. В современном учебнике этот прием практически повторен - русский студент, будучи человеком высокого роста, не может приобрести в японском универмаге одежду по своему размеру [3, с. 120-121]. Этот традиционный для русских акцент на разницу в физическом телосложении японцев и русских активно ис- 
пользовался ещё в сатирических лубочных картинах времен русскояпонской войны.

Однако то, что казалось новым в 1970-х гг. становится повтором в современном учебнике. Хотелось бы прочитать не просто описание достопримечательностей и получить информацию про политическое устройство Японии, но знать, как изменились гендерные отношения, что такое «травоядные мужчины» и почему японские женщины не хотят рожать детей, а предпочитают независимость, есть ли в Японии дискриминация в отношении этнических меньшинств, какие нововведения появились в службе быта, и как российская студентка, прожившая в Японии семь месяцев, берёт интервью у японского тренера. Некоторые из этих тем действительно фигурируют в учебнике, но «живой» современной Японии с ее культурой явно недостаточно.

Действующие лица текстов ограничиваются русскими студентами Анной и Сергеем и японской подругой Анны по имени Акико. Нигде не рассказывается, как студенты познакомились, что определяет их взаимный интерес друг к другу. Только ли книги и русский балет? Как они помогают друг другу и на чем это основывается? Предполагается, что читатели должны догадаться сами.

Учитывая ограниченность размера статьи, мы приводим контентанализ только двух тем - «Киото» и «Возвращение из Киото» (даны в одном уроке). Даже из отдельных слов видно, насколько описание экскурсий является стандартным. Маркером национальной идентичности русских является не только сам язык, но и географическая карта России (2), оренбургские платки (1), балет (1), Кремль (1), история России (1). Японские маркеры идентичности - Киото с его памятниками культуры (5), традиционная японская кухня (1), карта Японии (1) и в какой-то степени погода (1). Контент-анализ текста про поездку в Киото выглядит следующим образом.

Синкансэн (3), японская гостиница (2), экскурсионный автобус (1), путеводитель (1), столица (1), красные листья (2), политика (1), культура (2), ханами (2), дождь (1), праздник (2), обряд (2), гармония (3), наслаждаться (1), синтоистский храм (3), буддийский храм (1), Хэйан дзингу (5), строить (2), эпоха Хэйан (1), реставрация Мэйдзи (1), средство передвижения (1), шествие (2), японские сладости (2), современный (1), деревянный (2), национальное сокровище (2), окрестности (1) оригинальный (1), искусство (2), картина (2), сад камней (2) храм Рёандзи (2), «сухой» пейзаж (1), понимание (2), мир (1), быть взволнованным (1), маршрут (1) уникальный (1).

Текст этот написан с позиций «экскурсовода». На протяжении всей экскурсии студенты не задают ни одного вопроса и пассивно поглощают информацию. Надо сказать, что и в действительности экскурсии по достопримечательным местам Японии происходят именно так. Они проводятся под магнитофонную запись. Живая речь экскурсовода отсутствует. Объяснения не сопровождаются шутками или забавными историями. Сделать фотографии можно лишь в одномдвух определённых местах. Осмотр ограничен строгими правилами. Правда, так стали проходить экскурсии не только в Японии, но и во всем мире. Возможно, это стоило бы отметить.

По возвращении в Токио Сергей рассказывает о поездке своей квартирной хозяйке, которая в Киото никогда не бывала (что кажется неправдоподобным для японки), и говорит, что жители это- 
го города отличаются доброжелательностью от жителей Токио. Эту тему неплохо было бы развить. «Взгляд туриста» и нарочитая объективность изложения характерны и для других текстов учебника. Возможно, привлечение «третьей точки зрения» или рассказ какогонибудь исторического анекдота украсили бы изложение. В тексте же культура Киото идеализируется. На самом деле вовсе не обязательно давать только положительную характеристику культуры и ставшие стандартными рассказы, придерживаясь принципа одна страна одна культура. Показ разных культур, существующих в Японии, был бы интересен и дал бы больше возможностей для обсуждения и дискуссий [13].

Хотелось бы отметить, что в этом учебнике хорошо объясняется этикет, особенно на начальной стадии разговора, а также вежливые обороты на примере разговора с представителями сферы обслуживания. Большое внимание уделяется также объяснению и переводу грамматических маркеров эмоциональности -междометий и заключительных частиц, таких как حえ- (вопросительное значение: как? что?), ふーん (передает сомнение, соответствует русскому «хм»), え つ (выражает удивление), う一ん (размышление), うん (выражение согласия), じゃ (ну、тогда), そう (выражение согласия). Вспомним об этом, когда пойдет речь о «молчаливых японцах» [3, с. 88-89, 225-226, 316-317].

«Учебник японского языка для продолжающих» более глубоко раскрывает страноведческую тематику, производя как бы полное погружение учащихся в японскую культуру. Тексты включают такие темы, как японский язык, литература и история Японии, синто, суеверия (!), манга, японский сад, японская гостиница, архитектура и понятие цвета в Японии. Большинство текстов взято из журнала «Ниппониа». Подбор тем во многом позволяют понять ценности, лежащие в основе взглядов японцев на мир.

В тексте первого урока подчеркивается существование связи между лексикой, с одной стороны, и менталитетом людей, говорящих на этом языке, с другой. По мнению авторов, даже количество слов на определенную тематику в языке, может дать представление о восприятии природы, общества и человека данным коллективом людей. Так, в японском языке есть много слов, обозначающих дождь: «весенний дождь», «дождь в начале лета», «ливень» и прочее, есть даже такое понятие как «сезон дождей». Однако, остаётся не выясненным, свидетельствует ли это о том, что Япония дождливая страна, или, наоборот, о том, что дожди здесь «ценятся». Авторы статьи из «Ниппониа» также считают, что японцев можно назвать «молчаливой нацией» на том основании, что слова, обозначающие понятие «говорить», в японском языке имеют, как правило, отрицательный оттенок. Иностранцам трудно судить, как этот отрицательный оттенок проявляется, так что приходится полагаться на мнение японцев. [1, с. 11-12].

Короткий, но содержательный текст второго урока излагает историю японской литературы, подчеркивая, что благодаря тонкой чувствительности по отношению к природе в Японии издавна поэзия превалировала над прозой. Однако по мере появления на общественной арене горожан родились театральные и прозаические жанры, которые отражали борьбу между долгом и чувствами, корыстолюбием и честью. Повествуя о литературе нового времени, этот краткий 
экскурс обращает внимание учащихся не на широко известных всем писателях, стремившихся подражать Западу, вроде Нацумэ Сосэки, а знакомит с Хигути Итиё (1872-1896), героями произведений которой были молодые женщины, судьбы которых, как и самой писательницы, складывались непросто [1, с. 28-29]. Это наблюдение авторов должно быть интересно тем, кто интересуется гендерными вопросами.

В следующем тексте излагается история Японии с $\mathrm{V}$ века по Реставрацию Мэйдзи (1868 г.). В центре изложения стоит проблема смены центральной государственной власти (при сохранении института императорской власти), что хорошо известно. Однако примечательно, что отдельное внимание уделяется прибытию в Японию миссии адмирала Путятина в 1854 г. и студентам предлагается написать сочинение по теме "Становление российско-японских отношений». Это уже инициатива авторов учебника, а не журнала «Ниппониа». Дополнительные информационные материалы содержатся в приложении в конце учебника [1, с. 48-49].

В уроке четвёртом вновь говорится о связи, существующей между японцами и природой, на сей раз проявляющейся в религии. В Японии издавна считалось, что весь окружающий мир, все явления природы, наполнены богами. Это и было изначальное синто. Когда же в Японию пришел буддизм, две религии тесно переплелись, и до религиозных войн дело не дошло. Лишь единожды в истории - вскоре после Реставрации Мэйдзи - государство попыталось использовать синтоизм в своих целях, провозгласив государственный синто во главе с императором. Эта политика рухнула не только в связи с поражением Японии в войне, но и потому, что подобное отношение к синто было чуждо людям. Японцы радуются многочисленным красочным праздникам синто, которые скрашивают монотонность обычной жизни, определяют образ мышления и взгляд на мир [1, с. 62-63].

Любопытный текст под названием «Приметы, суеверия и гадания» содержится в пятом уроке. С точки зрения психологии, различные суеверия и приметы снимают страх и беспокойство, испытываемые перед чем-то неведомым, таким, например, как смерть. И в наш век науки люди продолжают надеяться, что манэки нэко (манящая кошка) поможет разбогатеть, деревянная дощечка дарума удачно сдать экзамен, а бумажки омикудзи предсказывают судьбу. Если же предсказывается неудача, от нее можно избавиться, оставив омикудзи в храме, повешенными на дерево. Пожалуй, в этом заключаются особенности суеверий японцев [1, с. 78-79].

В тексте шестого урока предлагается задуматься, почему в Японии так популярна манга не только среди детей, но и взрослых. С практической точки зрения, эти издания небольшого формата легко читать даже стоя в электричке. Хоть многие и считают, что манга является низкосортным чтивом, это не так. Опросы показывают, что манга создает эффект сопричастности и способна растрогать читателя и вызвать сочувствие не меньше, чем фильмы. Широко распространившись после войны, манга «взрослела» вместе с читателем, передавая переживания подростков и удачно приспосабливаясь к их запросам. Именно в этом главная причина того, что этот жанр составляет около $40 \%$ издательской продукции в Японии [1, с. 94-95].

Следующий урок посвящён существующему в Японии уникальному искусству создания каменных садов. В тексте рассказывается не 
только история развития этого вида искусства, представляющего, по сути, «сухой пейзаж», но объясняется и символическое значение его составных элементов. Столь непривычный европейскому взгляду и загадочный для европейцев японский каменный сад в определенной степени способствовал формированию представлений о Японии как необычной стране [1, с. 111-112].

Одним из наиболее впечатляющих текстов является рассказ, сопоставляющий японский рёкан с гостиницей западного типа (урок 8). Главное отличие между ними состоит в принципиально разном типе обслуживания. Если в западной гостинице оно основывается на требованиях и желаниях гостя, то в рёкане гость может ни о чём не думать, а полностью расслабиться, положившись на волю хозяйки. Одно действо сменяет другое по строго установленной очерёдности, но при этом гость всегда остается в кимоно, как бы не выходя за рамки частного пространства. Не является ли это одним из проявлений «амаэ», то есть положительного отношения к зависимости от другого, столь резко противостоящей западному индивидуализму? [1, с. 125-126].

Текст девятого урока представляет собой статью мэтра японской архитектуры и одного из членов известного движения «метаболизм» архитектора Курокава Кинсё. Он осуждает японцев за то, что они увлекаются городским дизайном вместо того, чтобы решать проблему перенаселения городов [1, с. 143-144].

Последний, десятый, урок повествует о принципиальных различиях в использовании цвета японцами и представителями Запада на Западе цвет используется для того, чтобы оживить материю, а в Японии для того, чтобы приглушить её. Данный тезис более подробно раскрывается на примере Виллы Кацура в Киото, где господствуют тень и освещение сзади, и мавзолея Тосёгу, где полихромное изображение фигур, как ни странно, работает как средство уничтожения чувства материальности [1, с. 158-159].

Темы текстов подобраны весьма удачно и позволяют студентам узнать не просто особенности японской культуры, но и получить объяснения о ценностных ориентациях, заложенных в ней.

Взятые все вместе они создают образ Японии как поэтической и несколько экзотической страны, где какие-либо социальные проблемы и связанные с ними волнения либо вовсе отсутствуют, либо легко устранимы - достаточно сходить в синтоистский храм либо расслабиться в рёкане. Люди в этой стране наделены даром чувствовать природу и понимать друг друга чуть ли не без слов. Однако после краха экономики «мыльного пузыря» такая Япония отошла в прошлое и сейчас на первый план вышли проблемы социального неравенства, деление людей на тех, у кого есть деньги, и тех, у кого их нет.

Идеализированное восприятие Японии существовало на Западе со времён открытия страны в середине XIX в. Появилось оно под влиянием увлечения японским искусством укиёэ, где выделялись пленительные изображения женщин и природы. На смену экзотической Японии в XX веке пришел её образ как воинственной страны, а по мере послевоенного экономического развития она стала видеться Западу уже как соперник в экономике.

Однако в позднесоветское время (1980-е гг.) в России преобладал образ Японии как «прекрасной страны» и для части советской интеллигенции переводы японской классики порой заслоняли реальную 
Японию [5, с. 171-191]. Замечено, что преподавателям свойственно испытывать влияние со стороны своего личного учебного опыта во время преподавания. Вероятно, авторы российского учебника сформировались как профессионалы именно в то время, когда в России существовала определенная «зачарованность» Японией и её культурой и такое восприятие отразилось на подборке текстов для учебника. Однако следует учитывать, что это лишь одна сторона образа страны.

\section{Заключение}

Рассмотренные учебники японского языка, как российского, так и японского происхождения, показали, что их авторы разделяют идею необходимости подачи культурологической проблематики. Однако в понимании того, что именно является культурной составляющей, есть существенные различия. Авторы японских учебников выбрали такой материал, который позволил им показать японскую культуру в сопоставлении с другими странами, поэтому их учебник даёт учащимся лучшую возможность стать культурно осведомленными людьми в международном масштабе. Авторы российских учебников сосредоточили внимание только на японской культуре, тем самым подчеркивая её уникальность. Это соответствует и задачам, которые ставят перед собой учебники. Контингент учащихся, которым адресован российский учебник, состоит в основном из тех, кому интересна Япония как страна сама по себе. Японский учебник рассчитан на более широкий круг учащихся, которым японский язык нужен как подспорье для работы и жизни в Японии и которые должны обладать навыками межкультурной компетенции.

Хочется отметить и важность того, как подается материал. Он всегда лучше усваивается, когда обучение происходит с юмором и шуткой, когда существует интерактивность между учащимися, учебником и преподавателем. Лучше, чтобы культурологические сведения соответствовали запросам настоящего времени и места, и были интересны многим. Например, информация о молодёжной культуре и фасонах одежды всегда увлекает студентов. Желательно избегать стандартных тем и не превращать учащихся в «туристов».

В Японии существует большой штат специалистов, готовых обслужить нужды учащихся иностранного происхождения. Деятельность составителей учебников японского языка поддерживается японским правительством, которое, учитывая демографическую ситуацию в Японии, заинтересовано в привлечении в страну иностранцев в качестве рабочей силы. В комплекте учебников «Японский для всех», состоящем сейчас из 19 томов, наверняка найдутся образцы для творческого заимствования.

\section{Литература}

1. Бессонова Е. Ю. Учебник японского языка для продолжающих, ч. 1. - М.: Московский лицей, 2009. 205 с.

2. Гуревич Т. М. Концепции обучения и учебные материалы по японскому языку // Японский язык в вузе. 2012. № 7. С. 2842.
3. Нечаева Л. Т. Учебник японского языка для начинающих, ч. 2. - М.: Московский лицей, 2002. 400 с.

4. Учебник японского языка (для продолжающих) / Ред. Головин И. В. - М.: Высшая школа, 1973. 302 с.

5. Штейнер Е. Больше не волшебная, 
но еще более привлекательная - меняющийся образ Японии в воображении русских // Япония и Россия. Национальная идентичность сквозь призму образов. Санкт-Петербург: Петербургское востоковедение. 2014. С. 171-191.

6. Ariawan S. Investigating Cultural Dimensions in EFL Textbook by Using Byram Checklist // Register Journal. 13(1), 2020, May. Pp. 123-152.

7. Dore R. The Internationalization of Japan // Pacific Affairs. Vol. 52, № 4 (Winter, 1979-1980). Pp. 595-611.

8. Hu G. Potential Cultural Resistance to Pedagogical Imports: The Case of Communicative Language Teaching in China // Language, Culture and Curriculum, Vol. 15 (2), 2002. Pp. 93-105.

9. Kanno Y. Kikokushijo as bicultural // International Journal of Intercultural Relations. Vol. 24, 2000. Pp. 361-382.

10. Kramsch C. The Cultural Component of Language Teaching // Language, Culture and Curriculum, 1995, 8:2. Pp. 83-92.

11. Kubota R. Critical Teaching of Japanese Culture // Shinji Sato and Neriko Musha Doerr, eds.) Rethinking Language and Culture in Japanese Education: Beyond the Standard // Multilingual Matters, 2008, 155. Pp.218-237.).
12. Reimann A. Critical Analysis of Cultural Content in EFL Materials, Research Papers of Utsunomiya University, 2009, Vol. 28. Pp. 85-101.

13. Sherlock Z. Japan's textbook inequality: How cultural bias affects foreign language acquisition // Power and Education. Vol. 8 (1), 2016. Pp. 73-87.

14. Weninger C., Kiss T. Language, Ideology and Education: The Politics of Textbooks in Language Education // Analyzing Culture in Foreign / Second Language Textbooks: Methodological and Conceptual Issues. CurtChristiansen, Xiaolan \& Weninger, Csilla. (Eds.). Routledge, 2018 [Kindle edition].

15. Wu Juan. A Content Analysis of the Cultural Content in the EFL Textbooks // Canadian Social Science, Vol. 6, № 5, 2010. Pp. 137-144.

16. みんなの日本語. 初級2. 本冊

(Японский для всех. Учебник для начинающих, часть 2. Основной том). スリーエ 一ネットワーク. 東京. - Токио: Корпорация 3А, 1998. 266 c.

17. みんなの日本語. 中級1. 本冊

(Японский для всех. Учебник для продолжающих, часть 1 . Основной том ). スリ 一エーネットワーク. 東京. - Токио: Корпорация 3А, 2008. 203 с.

Yulia D. MIKHAILOVA

$\mathrm{Ph}$. D. (in History), Honorary Professor of the Municipal University of Hiroshima (Japan).

Email: yuliamikjapan@gmail.com

\section{Cultural Component in Contemporary Japanese Language Textbooks}

UDC 81 doi: dx.doi.org/10.24866/2542-1611/2020-3/122-136

This paper analyzes cultural components of two Japanese cultural component, language textbooks, which were acknowledged to be the best textbook, during the student surveys carried out in Russia. The comparison Japanese language, of cultural components is based on the content analysis method introduced by M. Byram. The authors of the Japanese textbooks intercultural competence use materials, which allow them to examine Japanese culture in conjunction with other cultures. Therefore, their textbook provides an opportunity to raise students' cultural awareness in a broader international context. The authors of the Russian textbook concentrate on Japanese culture emphasizing only its "uniqueness" and attempt to reveal layers of culture and society that gave birth to values and peculiarities of mentality. 
Differences in the cultural components of the textbooks correlate with the goals of language education in each country. In Russia, textbooks aim at students who are interested mainly in Japan itself. In Japan, textbooks serve the needs of those who intend to live and work in Japan, so that intercultural competence for them becomes a must. The article provides some recommendations on how to engage students better in the process of learning culture.

For citation: Mikhailova YU. D. Cultural Component in Contemporary Japanese Language Textbooks // Oriental Institute Journal. 2020. № 3. P. 122-136. doi: dx.doi.org/10.24866/2542-1611/2020-3/122-136

\section{References}

1. Bessonova E. YU. Uchebnik yaponskogo yazyka dlya prodolzhayushhikh, ch. 1. - M.: Moskovskij litsej, 2009. 205 c.

2. Gurevich T. M. Kontseptsii obucheniya i uchebnye materialy po yaponskomu yazyku // YAponskij yazyk v vuze. 2012. № 7. S. 28-42.

3. Nechaeva L. T. Uchebnik yaponskogo yazyka dlya nachinayushhikh, ch. 2. - M.: Moskovskij litsej, 2002. $400 \mathrm{~s}$.

4. Uchebnik yaponskogo yazyka (dlya prodolzhayushhikh) / Red. Golovin I. V. - M.: Vysshaya shkola, 1973. $302 \mathrm{~s}$.

5. SHtejner E. Bol'she ne volshebnaya, no eshhe bolee privlekatel'naya menyayushhijsya obraz YAponii v voobrazhenii russkikh // YAponiya i Rossiya. Natsional'naya identichnost' skvoz' prizmu obrazov. Sankt-Peterburg: Peterburgskoe vostokovedenie. 2014. S. 171-191.

6. Ariawan S. Investigating Cultural Dimensions in EFL Textbook by Using Byram Checklist // Register Journal. 13(1), 2020, May. Rp. 123-152.

7. Dore R. The Internationalization of Japan // Pacific Affairs. Vol. 52, № 4 (Winter, 1979-1980). Rp. 595-611.

8. Hu G. Potential Cultural Resistance to Pedagogical Imports: The Case of Communicative Language Teaching in China // Language, Culture and Curriculum, Vol. 15 (2), 2002. Pp. 93-105.

9. Kanno Y. Kikokushijo as bicultural // International Journal of Intercultural Relations. Vol. 24, 2000. Pp. 361-382.

10. Kramsch C. The Cultural Component of Language Teaching // Language, Culture and Curriculum, 1995, 8:2. Pp. 83-92.

11. Kubota R. Critical Teaching of Japanese Culture // Shinji Sato and Neriko Musha Doerr, eds.) Rethinking Language and Culture in Japanese Education: Beyond the Standard // Multilingual Matters, 2008, 155. Pp.218-237.).

12. Reimann A. Critical Analysis of Cultural Content in EFL Materials, Research Papers of Utsunomiya University, 2009, Vol. 28. Pp. 85-101.

13. Sherlock Z. Japan's textbook inequality: How cultural bias affects foreign language acquisition // Power and Education. Vol. 8 (1), 2016. Pp. 73-87.

14. Weninger C., Kiss T.Language, Ideology and Education: The Politics of Textbooks in Language Education // Analyzing Culture in Foreign / Second Language Textbooks: Methodological and Conceptual Issues. CurtChristiansen, Xiaolan \& Weninger, Csilla. (Eds.). Routledge, 2018 [Kindle edition].

15. Wu Juan. A Content Analysis of the Cultural Content in the EFL Textbooks // Canadian Social Science, Vol. 6, № 5, 2010. Pp. 137-144.

16. みんなの日本語. 初級2. 本冊

(YAponskij dlya vsekh. Uchebnik dlya nachinayushhikh, chast' 2. Osnovnoj tom). スリーエーネットワーク. 東京. - Tokio: Korporatsiya 3A, 1998. $266 \mathrm{~s}$.

17. みんなの日本語. 中級1. 本冊

(YAponskij dlya vsekh. Uchebnik dlya prodolzhayushhikh, chast' 1 . Osnovnoj tom). スリーエーネットワーク. 東京. - Tokio: Korporatsiya 3A, 2008. 203 s. 